\title{
Location accuracy of VLF World-Wide Lightning Location (WWLL) network: Post-algorithm upgrade
}

\author{
C. J. Rodger ${ }^{1}$, J. B. Brundell ${ }^{2}$, and R. L. Dowden ${ }^{2}$ \\ ${ }^{1}$ Department of Physics, University of Otago, Dunedin, New Zealand \\ ${ }^{2}$ LFEM Research Ltd., 161 Pine Hill Road, Dunedin, New Zealand
}

Received: 2 June 2004 - Revised: 20 October 2004 - Accepted: 19 November 2004 - Published: 28 February 2005

\begin{abstract}
An experimental VLF World-Wide Lightning Location (WWLL) network has been developed through collaborations with research institutions across the globe. The aim of the WWLL is to provide global real-time locations of lightning discharges, with $>50 \%$ CG flash detection efficiency and mean location accuracy of $<10 \mathrm{~km}$. While these goals are essentially arbitrary, they do define a point where the WWLL network development can be judged a success, providing a breakpoint for a more stable operational mode. The current network includes 18 stations which cover much of the globe. As part of the initial testing phase of the WWLL the network operated in a simple mode, sending the station trigger times into a central processing point rather than making use of the sferic Time of Group Arrival (TOGA). In this paper the location accuracy of the post-TOGA algorithm WWLL network (after 1 August 2003) is characterised, providing estimates of the globally varying location accuracy for this network configuration which range over 1.9-19 km, with the global median being $2.9 \mathrm{~km}$, and the global mean $3.4 \mathrm{~km}$. The introduction of the TOGA algorithm has significantly improved the location accuracies.
\end{abstract}

The detection efficiency of the WWLL is also considered. In the selected region the WWLL detected $\sim 13 \%$ of the total lightning, suggesting a $\sim 26 \%$ CG detection efficiency and $\mathrm{a} \sim 10 \%$ IC detection efficiency. Based on a comparison between all WWLL good lightning locations in February-April 2004, and the activity levels expected from satellite observations we estimate that the WWLL is currently detecting $\sim 2 \%$ of the global total lightning, providing good locations for $\sim 5 \%$ of global CG activity. The existing WWLL network is capable of providing real-time positions of global thunderstorm locations in its current form.

Key words. Meteorology and atmospheric dynamics (Lightning; Atmospheric electricity; Instruments and techniques)

Correspondence to: C. J. Rodger

(crodger@physics.otago.ac.nz)

\section{Introduction}

Lightning discharges are powerful impulsive sources of electromagnetic energy over a wide bandwidth (well beyond the optical), with significant radiated electromagnetic power from a few hertz to several hundred megahertz (Magono, 1980), and the bulk of the energy radiated in the frequency bands $<30 \mathrm{kHz}$ (Pierce, 1977). Passive lightning location methods rely upon the energy released by the lightning discharge, acoustically (thunder), optically (lightning), and in the radio frequency spectrum (Uman, 1987). Today, commercial lightning location networks are in operation in many regions of the world, using multiple stations to locate the source of lightning electromagnetic radiation pulses (Rakov and Uman, 2003). The economic advantages that many groups obtain from accurate and virtually instantaneous lightning location data, results in this data being in high demand from many industries, such as electricity generators and distributors, aviation, forestry, sporting groups, insurance companies and weather forecasters (Cummins et al., 1998a). In addition to these groups, there is also strong scientific interest in the application of lightning data to a wide range of research topics, including lightning and related thunderstorm processes (Lyons et al., 1998), severe weather warning (Knupp et al., 2003), high altitude discharges (Rodger, 1999), global warming (Williams, 1992; Schlegel et al., 2001), regional meteorological processes (Hamid et al., 2001), production of important trace chemicals (Jourdain and Hauglustaine, 2001), determination of ionospheric parameters (Cummer et al., 1998), and losses from the Van Allen radiation belts (Rodger et al., 2003).

Multi-station lightning location systems generally consist of a number of spatially separated receiver stations positioned on the surface of the Earth (although some single station techniques also exist, e.g. Huang et al., 1999). The information from each station is, on its own, insufficient to enable the location of the discharge to be determined. However, when the information from some or all of the stations is combined together at a central site, the location of the discharge can be determined. An example is the United States National Lightning Detection Network 


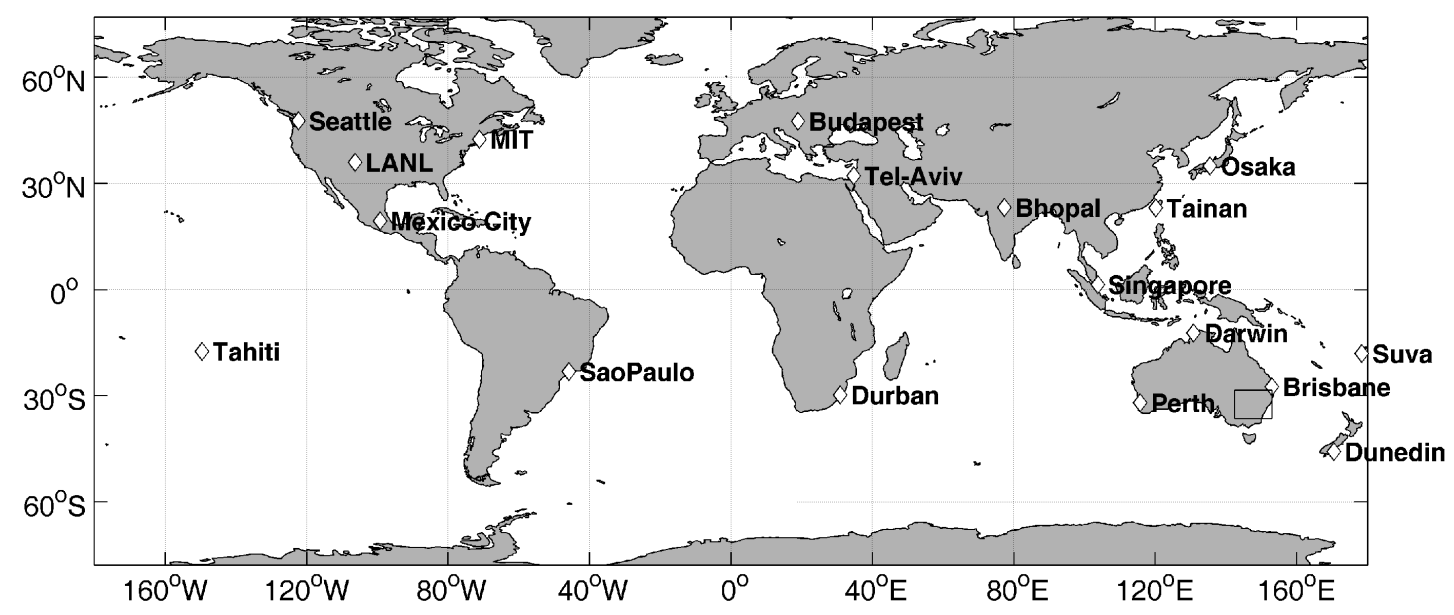

Fig. 1. Locations of the 18 VLF receiving stations (shown as diamonds) currently returning lightning trigger times to the processing stations (Dunedin and Seattle) as of mid-May 2004. The location of the WWLL Kattron comparison region is shown by the black square in Australia.

(NLDN), which in 1996 used 106 sensors located over the continental United States to achieve a typical accuracy of $0.5 \mathrm{~km}$ (Cummins et al., 1998b). Many commercial lightning detection networks require such high location accuracies to allow electrical power transmission companies to quickly locate lightning-produced line faults or to assist insurance inspectors in checking claims. Such networks rely upon the first few microseconds of the lightning pulse received in the MF band (0.3-3 MHz), thus avoiding the sky wave (that which reflects from the ionosphere), and processing only the ground wave (which has high attenuation at the high frequencies used). Thus, NLDN requires $>100$ ground stations to cover the contiguous US $\left(\sim 10^{7} \mathrm{~km}^{2}\right)$, corresponding to a ground station density of $\sim 10 \mathrm{Mm}^{-2}$. Such a high density of stations makes these systems poorly suited for coverage of areas with low population density (leading to financial constraints), or economic development, or across the oceans.

Low-Frequency Electromagnetic Research Ltd. has created an experimental VLF World-wide Lightning Location (WWLL) network through collaborations with research institutions across the globe (Fig. 1 shows the current network configuration). The network exploits the considerable electromagnetic power radiated by lightning as "sferics" present in the VLF band (3-30 kHz). Very long range remote sensing is possible; these VLF signals can be received thousands of kilometres from the source (Crombie, 1964), as the electromagnetic energy propagates with low attenuation inside the waveguide formed by the conducting Earth and the lower boundary of the ionosphere, termed the Earth-Ionosphere Waveguide (EIWG). The vertical electric field from strong lightning dominates over power line noise in the receiver bandwidth $(6-22 \mathrm{kHz})$, such that the WWLL receiving stations have relative freedom from the restriction of noise-free receiver locations required for other long-range lightning location techniques (e.g. Fullekrug and Constable, 2000). The use of differing sferic frequency ranges in multi-station lightning location networks has been discussed by Cummins and
Murphy (2000) and Dowden et al. (2002). The aim of the WWLL is to provide real-time locations of cloud-to-ground lightning discharges occurring anywhere on the globe, with $>50 \%$ flash detection efficiency and mean location accuracy of $<10 \mathrm{~km}$.

In the initial testing phase of the WWLL network (preAugust 2003), the stations operated in a simple mode, sending the trigger time, relative to GPS, back to the central station (in Dunedin, New Zealand) for processing, to produce a lightning location. The location accuracy and detection efficiency of the early network configuration was tested by contrasting WWLL network locations over 2 days in January 2002 with those from a commercial lightning location system, Kattron, based in Australia (Rodger et al., 2004). The data sets were limited to a relatively small part of Australia where Kattron has its highest performance, with location accuracies of $\sim 1 \mathrm{~km}$ or better and $>80 \%$ detection efficiency for Cloud-to-Ground (CG) lightning discharges. After this selection there were 426 matched lightning events, corresponding to lightning discharges with large lightning return stroke peak currents. The WWLL network detected events had a mean absolute peak current of $\sim 26 \mathrm{kA}$ compared with $\sim 12 \mathrm{kA}$ for all Kattron events. This reflects the very low detection efficiency of the WWLL network at this time $(\sim 1 \%)$, when the triggering thresholds were set high to avoid network saturation. By considering the random errors in the difference locations between the matching lightning events, an appropriate Gaussian timing error for the WWLL network of receiving stations was determined $(\sim 35 \mu \mathrm{s})$, allowing an estimate of the global location errors for the then 11-station network to be calculated, and presented as location accuracy maps. The "worst-case" global location error found ranged spatially from $7.5-100 \mathrm{~km}$, with the global median being $15 \mathrm{~km}$, and the global mean $30 \mathrm{~km}$.

The location accuracy of the WWLL network has also been tested by contrasting March 2003 commercial lightning data from Brazil (Lay et al., 2004). At this time all 
the VLF lightning receivers in the network were very distant $(>7000 \mathrm{~km})$ from the thunderstorms. This study found that WWLL detection was highly dependent upon the peak return stroke current, resulting in a $0.3 \%$ stroke detection rate favouring strokes of $>50 \mathrm{kA}$. The detected strokes had a location accuracy of $20.25 \pm 13.5 \mathrm{~km}$, consistent with the maps given in Rodger et al. (2004), with temporal accuracy of 0.06 $\pm 0.2 \mathrm{~ms}$. Lay et al. (2004) concluded that the WWLL network data could provide spatial resolution on the order of magnitude of an isolated thunderstorm even at $>7 \mathrm{Mm}$ from the receiver locations, allowing an indication of global lightning activity in real time (if not individual flashes).

For many scientific applications, the benefits of a global overview in real time can outweigh the very low total lightning detection. Observations of red sprites undertaken from the space shuttle Columbia during the ill-fated STS107 mission used WWLL activity maps available from the Internet to orientate the shuttle (Yair et al., 2004), allowing for some predication of where active thunderstorms containing the large lightning events which produce red sprites would be located.

On 1 August 2003 the WWLL network was upgraded to make use of a new timing algorithm to compensate for the dispersion of the VLF sferic due to EIWG propagation. Propagation over long ranges in the EIWG disperses the initial sharp pulse of the lightning stroke into a wave train lasting a millisecond or more. The amplitude of the received sferic wave train rises slowly (over a few hundred microseconds) from the noise floor, so there is no sharp onset and no sharply defined Time of Arrival (TOA) at the receiving station. In the new algorithm a measurement is made of the time of group arrival (TOGA) of the sferic wave train received at each station, determined relative to GPS at each site from the progression of phase versus frequency using the whole waveform (Dowden et al., 2002). The TOGA method avoids the requirement of transmitting the entire VLF waveform back to a central station for processing; the lightning locations can be determined from differences in the TOGA times using well developed residual minimization methods employed in location techniques based on arrival time differences (e.g. Lee, 1986). The introduction of the TOGA method means that dispersion due to VLF propagation is now much less important in the observations (in theory, such dispersion is removed altogether), such that the uncertainties in arrival times should now be independent of the distribution of lightning sourcereceiver distances. As the waveform need not be transmitted, Internet costs associated with long-range lightning location data-transfers are decreased, and "normal" Internet transmission (e.g. User Datagram Protocol)) can provide acceptable real-time lightning location $(<10 \mathrm{~s})$ without the requirement of special broad-band connections.

In this paper we characterise the location accuracy of the post-TOGA algorithm WWLL network, by comparing the WWLL locations with lightning location data which were purchased from the Kattron commercial Australian lightning location network. This therefore provides a direct contrast between the pre-TOGA algorithm WWLL network location accuracies considered by earlier studies. We go on to estimate the location accuracy of the global network of WWLL receiving stations as currently operating, and estimate the detection efficiency of the existing network.

\section{WWLL network description}

The basic operation of the WWLL receiving stations, the location finding process, and TOGA calculation are described in Dowden et al. (2002), while network operation issues associated with stroke selection and data management have been discussed in Rodger et al. (2004).

\subsection{VLF receiving stations}

All of the current VLF WWLL receiving stations are located in built-up areas unsuitable for use of magnetic loop antennas at VLF, because power line interference will dominate over the magnetic field of the sferic. However, this is not true for the sferic electric field because at VLF even poor conductors such as ferroconcrete buildings, remain at ground potential and shield man-made electric fields generated within them. Consequently, the WWLL receiving stations require only a short $(1.5 \mathrm{~m})$ whip antenna on a tall building to measure the vertical electric field of the sferic TM waveguide mode. At the time of writing, the WWLL network consists of 18 receiving stations shown as diamonds in Fig. 1 and listed in Table 1. Dual processing stations are located in Dunedin (New Zealand) and Seattle (USA). Further receiver stations are planned for South America and Central Asia. However, as seen in Fig. 1, the stations are far from being uniformly spaced, despite the rapid growth over the last 3 years. The network P. I. (R. L. Dowden) would be pleased to hear from anyone who could help bridge the larger gaps, particularly in and around Africa. The lightning receiving station at each research institute is provided by the project but each host meets local costs (processing computer and Internet). In return, the hosts are provided with archival lightning data from the world-wide network.

\subsection{Sferic selection}

Rodger et al. (2004) reported on the algorithm by which each timing measurement from the stations are combined to select a common stroke. This process is still used, although with TOGA measurements rather than TOAs. The Rodger study also outlined the maximum trigger rate limitation used to prevent a single receiving station from flooding the processing stations with bad observations, such that no sensible lightning location estimates are possible. It should be noted that in practise this means that thunderstorms occurring nearby (maybe $\sim 100 \mathrm{~km}$ ) from a station will significantly degrade the information from that station, as most of the triggers will only be "local" to that station. In addition to the limitation on the maximum trigger rate, receiving stations now undertake tests on the observed sferic before passing the TOGA back for processing. As part of the processing of each sferic at the 
Table 1. Locations and hosts of the 18VLF receiving stations currently operating in the VLF World-wide Lightning Location Network.

\begin{tabular}{lrrl}
\hline Location & Latitude $(\mathrm{N})$ & Longitude $(\mathrm{E})$ & Host \\
\hline Dunedin & -45.8639 & 170.514 & University of Otago \\
Darwin & -12.3718 & 130.868 & Northern Territory University \\
Brisbane & -27.5534 & 153.052 & Griffith University \\
Perth & -32.0663 & 115.836 & Murdoch University \\
Osaka & 34.8232 & 135.523 & Osaka University \\
Singapore & 1.2971 & 103.779 & National University of Singapore \\
Tainan & 22.9969 & 120.219 & National Cheng Kung University \\
Budapest & 47.4748 & 19.062 & Eötvös University \\
Seattle & 47.654 & -122.309 & University of Washington \\
MIT & 42.3604 & -71.0894 & Massachusetts Institute of Technology \\
Durban & -29.8711 & -40.9764 & University of Natal \\
Sao Paulo & -23.2075 & 178.4459 & INPE \\
Suva & -18.1489 & -106.328 & University of the South Pacific \\
LANL & 35.8721 & 77.4363 & Barkatullah University \\
Bhopal & 23.2146 & -99.1764 & Universidad Nacional Autonoma de Mexico \\
Mexico City & 19.3261 & -149.609 & Universite de la Polynesie Francais \\
Tahiti & -17.5767 & 34.8062 & Tel Aviv University \\
Tel Aviv & 32.1130 & & \\
\hline
\end{tabular}

receiving station, a measurement is made of sferic dispersion (caused by propagation in the EIWG). While the dispersion can be zero (as it is for the TEM mode, or for short distance propagation in any mode), no genuine physical cause can make the dispersion negative. Thus, only events with non-negative dispersion are treated as real sferics, and their TOGA is transmitted to the processing stations. Spurious events fail this test, and may be due to man-made interference (e.g. electric fences), two sferics overlapping in time at the receiver, or from one sferic being poorly distorted by modal interference. While the latter cases are not strictly "unreal" sferics, they are examples of situations where the TOGA calculation (Dowden et al., 2002) will not be meaningful. It is important to point out that most spurious effects affect a single station at a given moment: sferics from different strokes, Mms apart, are unlikely to overlap at more than two stations at the same time; man-made pulses are likely to be local and appear at only one station; interference peaks from two or more VLF transmitters momentarily in phase cannot appear at two stations at the same time. While genuine sferics may be discarded at one station, the stroke is not necessarily lost, provided that at least 4 other stations observe the sferic. The limitations above serve to decrease the processing load on the processing stations and avoid unnecessary Internet charges.

\section{Comparison with commercial lightning location data}

We have re-examined the location accuracy of the WWLL network after the implementation of the TOGA algorithm, by making a comparison with Kattron commercial lightning locations following the pre-TOGA algorithm approach outlined in Rodger et al. (2004).

\subsection{Kattron lightning location data}

Kattron, an Australian based company, operates a commercial TOA (Time of Arrival) lightning location network, using a network of 7 LPATS TOA receivers (Cummins et al., 1998 b), positioned to achieve sub-kilometre location accuracy and high detection efficiencies $(>80 \%)$ over most of the regions of Australia with high population densities, located in the south-east of the country. A description of the location accuracies and detection efficiency of this network has been presented earlier (Brundell et al., 2002; Rodger et al., 2004). Kattron data was purchased for 13 January 2004. This day was selected on the basis of WWLL network observations showing strong thunderstorm activity inside the Kattron 7-station network. The data purchased included locations for all the lightning strokes located by Kattron on this UT-day, and thus many well outside the Kattron receiver network. Following Rodger et al. (2004), the Kattron data set was limited to a region in SE Australia where the modelled Kattron rms location accuracy is $\sim 1 \mathrm{~km}$ or better, and the $\mathrm{CG}$ detection efficiency is $>80 \%$ (Brundell et al., 2002).

The 19313 CG strokes reported by Kattron inside this region on 13 January 2004 are shown as black dots in the right-hand panel of Fig. 2. Also shown in this panel are red dots, indicating the locations of 869 Kattron-reported intracloud (IC) lightning flashes (sometimes simply termed "cloud flashes"). In general, it is understood that there are 3.5 times more IC lightning flashes than CG flashes (Mackerras et al., 1998), and thus one might expect there to be considerably more IC events present in Fig. 2. However, the LPATS receiver technology is strongly focused towards the detection and accurate location of the stronger CG discharges, and has a fairly low IC detection efficiency. For 

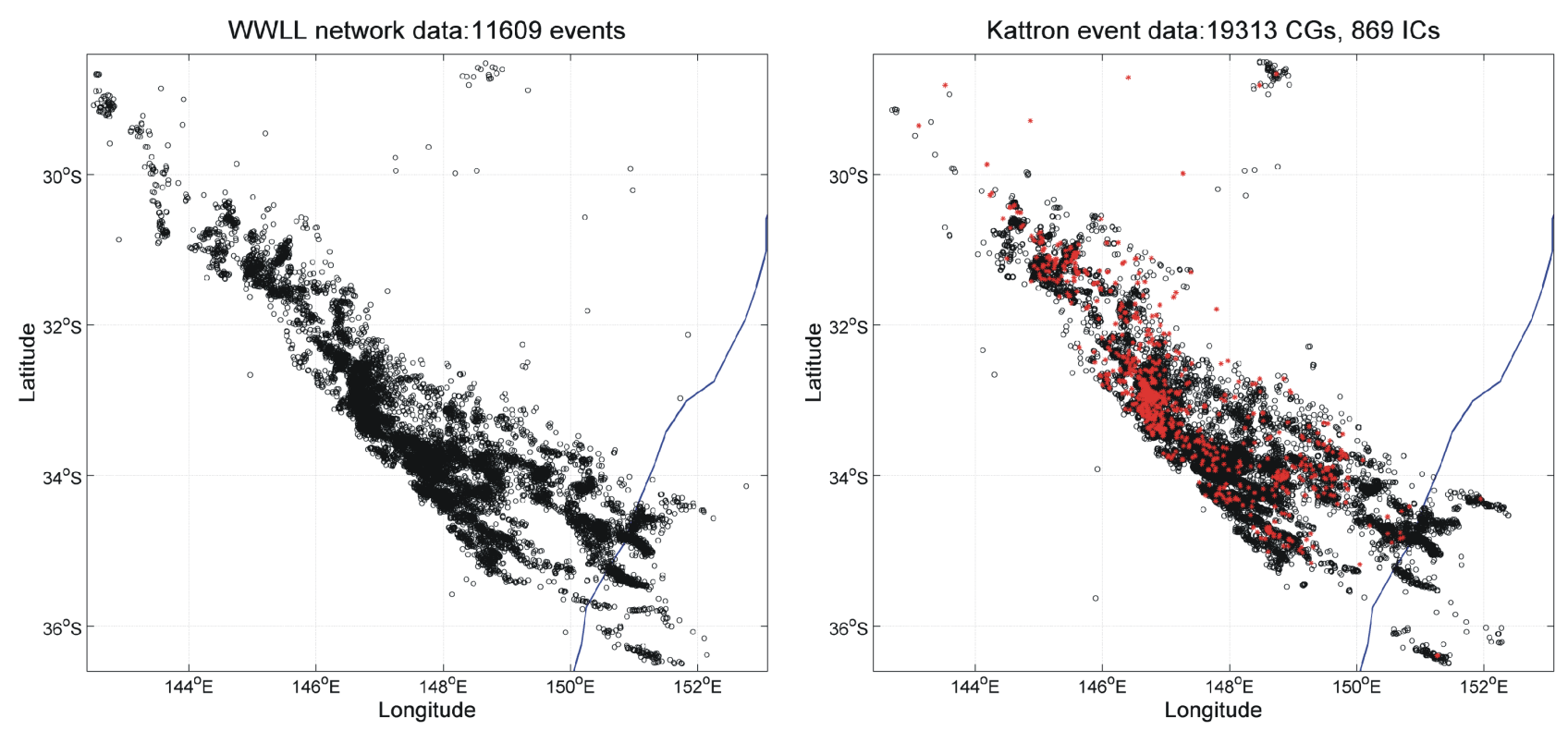

Fig. 2. Positions of lightning events on 13 January 2004 detected inside our selected region by the WWLL network (11 609 events, left panel) and Kattron (19313 CGs, right panel). The WWLL data has been restricted to "good" location data ( $\leq 20 \mu \mathrm{s})$. The red dots in the Kattron panel show cloud discharge locations ( 869 events), while the blue line in both panels is part of the east coast of Australia.

example, the Canadian Lightning Detection Network has a $1-4 \%$ detection efficiency for cloud flashes (roughly consistent with the apparent Kattron IC efficiency), while the detection efficiency for ground flashes is $85-90 \%$ (Burrows et al., 2002). On 13 January 2004 Kattron reported a total of 22,347 CG discharges, some as far away as Borneo. This total is only $\sim 15 \%$ larger than that reported by Kattron in the selected region, indicating the strong fall off in detection efficiency beyond the ring of Kattron receivers located in SE Australia. A similar situation exists with the NLDN beyond the continental United States.

The lightning activity seen in Fig. 2 occurs almost entirely during the daylight hours, such that we cannot examine local diurnal variations from VLF propagation effects. However, note that signal attenuation for VLF propagation is higher for the daytime ionosphere than for the night, as this would be the worst case (albeit when most lightning also occurs).

\subsection{WWLL network lightning location data}

Figure 2 also shows the lightning discharge locations reported by the WWLL network inside the selected region on 13 January 2004. In the WWLL-employed location algorithm, a residual time is provided for each event, providing an indication of the error remaining after the minimization processes has produced a location (e.g. Lee, 1986). In our analysis only the 11,609 WWLL events with low residuals $(\leq 20 \mu \mathrm{s})$ were included (as shown in Fig. 2), providing a fairly strict requirement for "good" lightning locations. Twenty microseconds is currently the LF*EM suggested residual threshold for "good" lightning, and is somewhat smaller than the $50 \mu$ s limit employed by Rodger et al. (2004). The number of WWLL events on this day in our region changes by only $\sim 10 \%$ if the higher threshold is employed.

A comparison between the 2 panels of Fig. 2 indicates that the WWLL network appears to be very successful at tracking thunderstorms. The overall form of the figures is very similar, and much of the fine structure in lightning activity levels is present in both panels. While this is no substitute for a stroke-by-stroke comparison (undertaken below), it appears to confirm the conclusion that the WWLL can provide accurate tracking of large-scale electrical phenomena (Lay et al., 2004), such as the discharges in a frontal squall line seen in this figure.

\subsection{Coincident lightning}

In order to make comparisons between the location estimates for CG lightning discharges by the Kattron network and WWLL network data, WWLL events were selected which occurred within $\pm 3 \mathrm{~ms}$ and $50 \mathrm{~km}$ of a lightning event detected by Kattron inside the selected region, where the WGS84 Ellipsoid was used to determine the distance difference. The choice of the time/space window limits are rather arbitrary, but follow those used in earlier studies (Rodger et al., 2004; Lay et al., 2004). On the basis of the following results we argue that these time/space limitations are sufficient to determine all matching events in the two data sets. Under these restrictions a total of 5006 matching lightning events were found, i.e. that the WWLL network detected $\sim 26 \%$ of the CG discharges reported by the Kattron network. Note that this is a very large increase from the pre-TOGA algorithm study, where only $\sim 1 \%$ detection efficiency was found, 


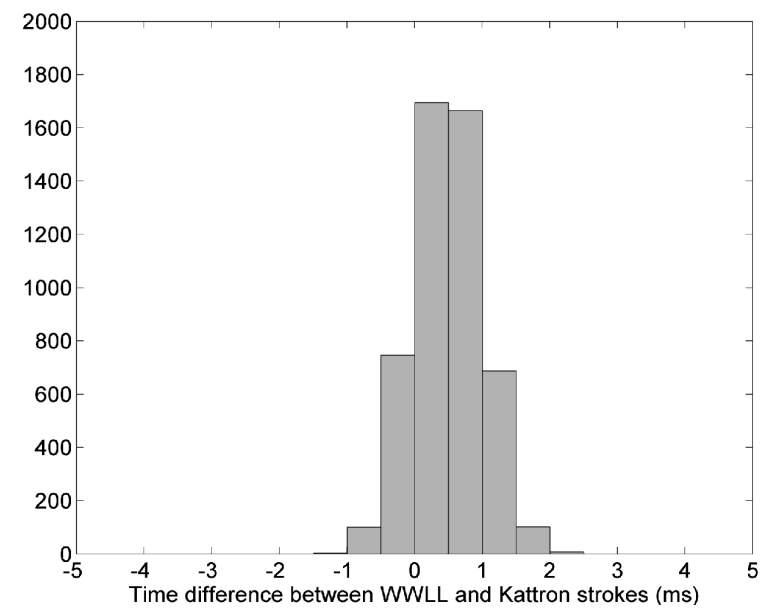

Fig. 3. Absolute value of the time differences (WWLL - Kattron) between the 5006 matching events detected by the WWLL and Kattron networks.

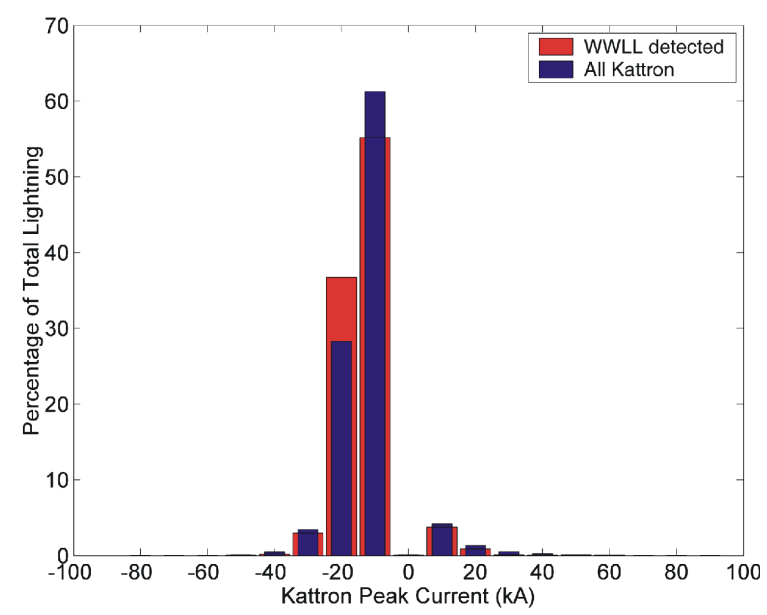

Fig. 4. Distribution of return stroke peak currents determined by the Kattron lightning network. The dark bars show the distribution for all Kattron lightning events, while the lighter events show the current distribution for those events which were also detected by the post-TOGA WWLL network.

albeit during a period when the triggering thresholds were set high. The time differences between the Kattron and WWLL events are shown in Fig. 3 where the mean time difference is $0.49 \mathrm{~ms}$. The distribution peaks at $\sim 0.5 \mathrm{~ms}$ as the Kattron data is provided with 1-ms resolution, while the WWLL lightning data has $1-\mu$ s resolution. This rounding of the Kattron event times means that we expect a systematic 0.5 -ms difference between coincident events given in the two data sets. Note that there are almost no matching lightning events with time differences greater than $\pm 2 \mathrm{~ms}$, giving us good confidence that we are correctly identifying coincident lightning observations.

The distribution of Kattron-detected lightning return stroke peak currents are shown in Fig. 4 (blue bars). Note that the Kattron-estimated return stroke peak currents are

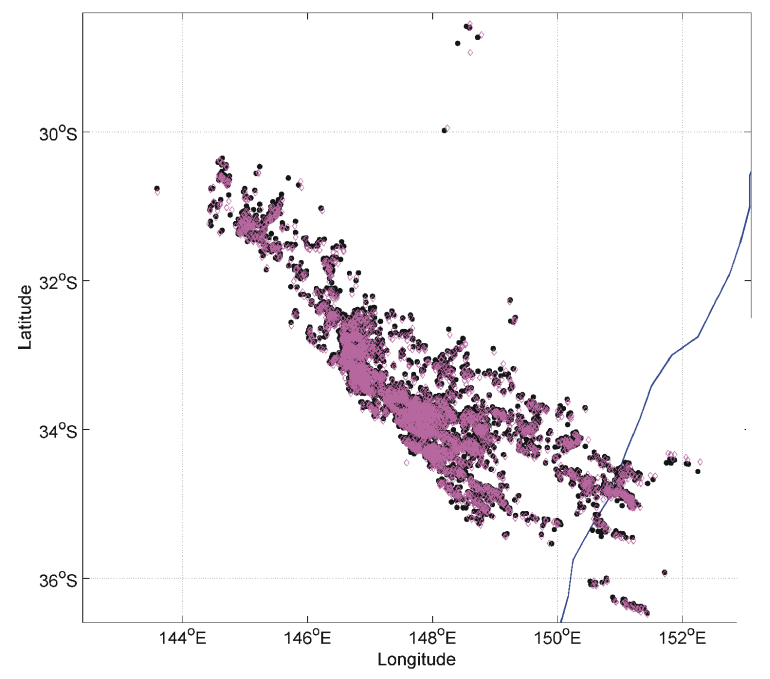

Fig. 5. The positions of the matching lightning events as determined by the Kattron (magenta diamonds) and WWLL data sets (closed circles), in the same format as Fig. 2.

based on lightning return-stroke speeds, and as measured return-stroke speeds typically have uncertainties of $\pm 50 \%$ (see MacGorman and Rust, 1998), it should be noted that these currents may carry the same uncertainty. However, it appears that the currents reported by the US NLDN are more accurate than this uncertainty would suggest. Direct measurements of triggered lightning indicates that NLDN may actually underestimate lightning currents by around $\sim 20 \%$ (Vladimir Rakov, personal communication, 2004).

As expected, the majority of cloud-to-ground (CG) strokes detected by Kattron are of negative polarity and relatively small peak currents, with the mean absolute peak current for all 19313 CG strokes detected on these 2 days being $13.8 \mathrm{kA}$ and $\sim 6.5 \%$ of the discharges having positive polarity. The red bars in Fig. 4 show the Kattron determined peak currents for the lightning events which were also detected by the WWLL network. While this plot suggests that the WWLL network tends to detect CGs with larger return stroke peak currents, the mean absolute current for the agreed events is $14.3 \mathrm{kA}$, essentially the same as the Kattron data set. This is a major change from the pre-TOGA network data, where the mean absolute peak current of the matching events was $\sim 26 \mathrm{kA}$. However, this change is to be expected, as it reflects the much higher detection efficiency of the WWLL in the current study.

\subsection{Location differences between the two networks}

The positions of the 5006 matching lightning events as determined by the Kattron (magenta diamonds) and WWLL data sets (closed circles) are shown in Fig. 5. The clustering in this figure is very high, such that generally the two data sets lie on top of one another. From the clustering of matching event locations it appears that the WWLL network is successfully determining the location of lightning discharges with 
much improved accuracy. The pre-TOGA WWLL network showed a strong eastwards offset relative to Kattron (Rodger et al., 2004), which was not present in the Brazilian comparison (Lay et al., 2004). At the time it was suggested that the eastwards offset present in the Australasian sector might be a consequence of an interference problem at the Dunedin station, corrected in July 2003. This problem appears to be associated with the hardware/software combination of the Dunedin based CPC and WWLL receiving station. Once these duties were split between two fresh machines, the problem seems to have disappeared. Figure 5 suggests that this offset has been corrected. This is confirmed in Fig. 6, which shows the east-west and north-south contributions of the WGS-84 Ellipsoid determined distance differences between the matched locations (WWLL minus Kattron). The dotted lines indicate the median values of the differences. These have been displaced $\sim 2.8 \mathrm{~km}$ northwards and $\sim 0.9 \mathrm{~km}$ westwards, both less than the standard deviations in the offsets $(3.5 \mathrm{~km}$ north-south and $2.7 \mathrm{~km}$ eastwards), and significantly less than the total scatter in Fig. 6. There are now no statistically significant systematic offsets present in this region.

\subsection{Random errors in the WWLL network}

The random error present in the scatter of the differences in Fig. 6 is described by the mean $(4.2 \mathrm{~km})$ and standard deviations $(2.7 \mathrm{~km})$ in the location differences. As the error in the lightning locations in the Kattron data should not be correlated with the error in the location deduced in the WWLL network data, we can assume that the random errors in the two data sets are independent. Thus, it can be said that,

$\sigma_{m}^{2}=\sigma_{\text {Kattron }}^{2}+\sigma_{\mathrm{WWLL}}^{2}$,

i.e. the variance of the differences between the two data sets is equal to the sum of the variances of the error in each method. As the Kattron location error will vary across our selected region, we will take a conservative approach to estimating the WWLL network errors, and take $\sigma_{\text {Kattron }}=0$, i.e. treat the Kattron locations as having no significant error. In this case $\sigma_{m}$ should indicate the location error for "good" lightning locations provided by the WWLL network in our selected region.

We employ a "Monte Carlo" style simulation to obtain an estimate of the location accuracy for the WWLL network (following Rodger et al., 2004). This is undertaken at each position of interest by determining the location errors for 400 (simulated) lightning discharges from which the standard deviation of the distribution of errors is recorded as an estimate of the location accuracy of the network at that location. The above method has been implemented assuming that the errors in the location network may be modelled as Gaussian with a user-specified standard deviation, that is, described by a Gaussian timing error. Thus, the individual timing errors for each simulated discharge at each location are randomly sampled from a normal distribution with standard deviation given by the Gaussian timing error. Following this Monte Carlo

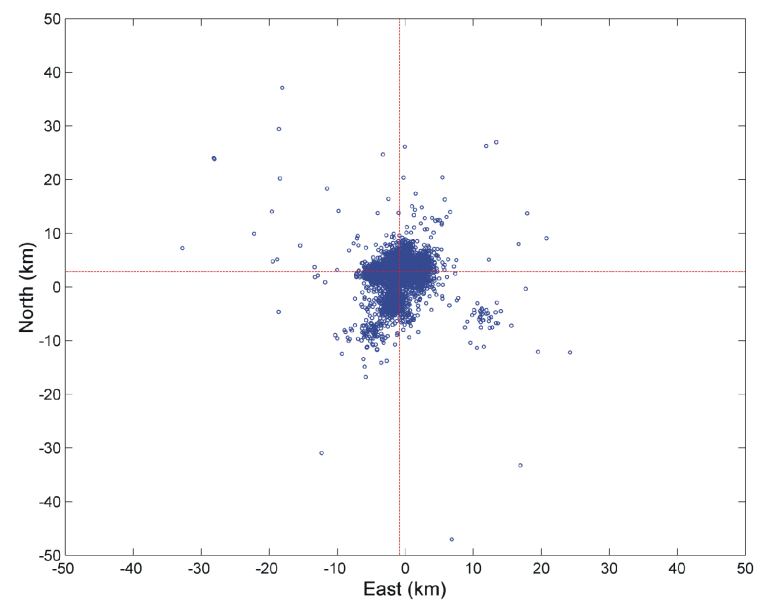

Fig. 6. The east-west and north-south distance differences between the 5006 lightning event locations (WWLL minus Kattron). The dotted lines indicate the median values of these differences.

location accuracy modelling we find that the representative Gaussian timing error for the post-TOGA algorithm WWLL network is $\sim 10 \mu \mathrm{s}, 3.5$ times better than the pre-TOGA algorithm network. Clearly, the introduction of TOGA processing has led to large improvements in the location accuracy of the network, as expected. This is consistent with the mean of the matched WWLL events' residual timing errors, which is $8.9 \mu \mathrm{s}$. Maps of the global lightning location accuracies determined using this timing error are presented in Sect. 5.

The primary improvement in the location accuracy will be due to the introduction of the TOGA algorithm, mitigating the effects of sferic dispersion due to propagation in the EIWG. A detailed description of the difference between the TOGA and TOA timing has been presented by Dowden et al. (2002), who also give examples of the dispersion expected over the $6-22 \mathrm{kHz}$ bandwidth of the WWLL station receivers. A more detailed calculation has been shown by Rodger et al. (Fig. 9, 2004) who consider the importance of the east-west anisotropy in this region.

\section{Extra events in WWLL network data}

In addition to the 5006 matching events found in the two data sets, there were also 6603 WWLL events, shown in Fig. 7, which did not match a Kattron lightning location. As the Kattron network is believed to have a $>80 \%$ CG detection efficiency in our selected region, it is inconceivable that all of these unmatched events are missed CG discharges. However, as is clear from Fig. 7, the unmatched events are located in the same locations where CGs have been detected, and track out the same thunderstorm paths seen in Fig. 5 (and the right panel of Fig. 2). Thus, it appears that the WWLL is detecting discharge events occurring inside thunderstorms which are not CGs. Similar sets of unmatched WWLL locations were noted by Rodger et al. (2004) $(\sim 65 \%$ as numerous as the matched CGs) and Lay et al. (2004) ( 130\%). In the 


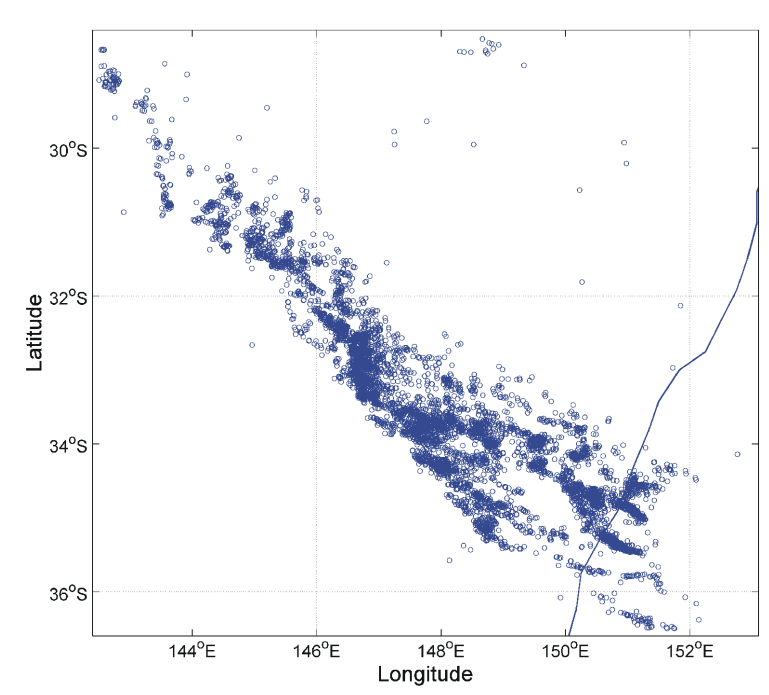

Fig. 7. The positions of the 6603 unmatched locations from the WWLL data set (blue circles), in the same format as Figs. 2 and 5.

latter case the authors reported that a balloon-borne VLF receiver operating in Brazil detected a sferic within $1 \mathrm{~ms}$ of the unmatched WWLL event. On this basis the previous authors have argued that the unmatched events are lightning discharges, but are probably cloud discharges rather than CGs. An experimental VLF lightning location network operated in the US detected $\sim 65 \%$ of CG discharges and $\sim 13 \%$ of IC discharges (Morales et al., 2004), such that roughly half the events detected were due to IC discharges. This would be roughly consistent with our finding, where the unmatched event set is $\sim 130 \%$ the size of the matched set of CG discharges. VLF observations of sferics made at Palmer station, Antarctica, believed to be from a storm in the southern USA, have been contrasted with CG observations made by NLDN (Wood and Inan, 2002), leading the authors to conclude that both ICs and CGs were present in the Palmer sferic data.

As noted above, the Kattron network detects some cloud flashes, and reported 869 IC discharges on 13 January 2004 in our selected region, allowing another check as to whether our unmatched events are real IC lightning. Of these Kattron IC discharges, 8 are found to match with the 6609 remaining WWLL events, using the same time and distance separations in Sect. 3.3. In addition, we can also consider satellite observations as an extra "ground truth" data set.

The Lightning Imaging Sensor (LIS) aboard the Tropical Rainfall Measuring Mission satellite detects lightning optically by observing the neutral oxygen line at $777.4 \mathrm{~nm}$ (Orville, 1995). Comparisons of LIS, NLDN, and VHF radar lightning observations found that the LIS tends to detect cloud-to-ground (CG) discharges towards the end of the discharge process, probably the late stage in-cloud components of the CG discharge, occurring in the upper parts of the thundercloud. Differences of $\sim 1 \mathrm{~s}$ were possible between the NLDN and LIS detections (Thomas et al., 2000). While such timing differences will make it difficult to make direct comparisons between the WWLL locations and those ob- served by satellite, we have examined the LIS flash observations during 2 passes over our selected region, and looked for events occurring within $25 \mathrm{~ms}$ and $50 \mathrm{~km}$ of a Kattron or WWLL event. During these passes the LIS detected 248 flashes, 9 of which are found in the Kattron data set (of which 2 are present in the matched WWLL locations). We find that 9 unmatched WWLL events occur within $25 \mathrm{~ms}$ and $50 \mathrm{~km}$ of a LIS flash, with a mean separation of $\sim 9 \mathrm{~km}$. This compares favourably with the LIS location error or expected uncertainty of $6-8 \mathrm{~km}$. These observations provide strong evidence that the unmatched WWLL events are indeed caused by IC discharges.

Kattron detected 19,313 CGs in our selected region on 13 January 2004. Assuming that there are 3.5 times more IC discharges than CG, and that the Kattron detection efficiency is $100 \%$, there should have been about 67600 IC discharges, such that the total lightning activity $(\mathrm{CG}+\mathrm{IC})$ should have been about 86900 lightning discharges. Of these, the WWLL detected $\sim 13 \%$ of the total lightning, suggesting a $\sim 26 \%$ CG detection efficiency and a $\sim 10 \%$ IC detection efficiency in this region. It is not a surprise that the CG detection efficiency is higher than that for ICs, as peak currents (and current moments) in CG flashes tend to be larger than for IC flashes (Uman, 1987). Furthermore, many IC flashes can be quite small in extent (e.g. Rakov and Uman, 2003), whereas a threshold distance must be achieved for a CG flash bridging the main negative charge reservoir and ground. While the detection efficiencies estimated above are lower than the long-term goal of the network, they represent a considerable improvement from the earlier (pre-TOGA algorithm) detection efficiencies reported by Rodger et al. (2004). We should caution that our selected region has a relatively high WWLL station density, and these detection efficiencies will not hold in general (global rates are considered in Sect. 6). However, there are some high lightning activity regions, such as North America, which have similar station densities as Australasia, and thus could have somewhat similar detection efficiencies.

\section{Global location accuracy}

The analysis above has provided us with an estimate for the timing error of the WWLL network. Following the Monte Carlo process outlined in Rodger et al. (2004) we can estimate the global lightning location accuracies for the entire network of 18 receiving stations listed in Table 1, assuming that only the minimum number of receiving stations (taken to be the 4 nearest stations) is involved in each location finding process. This is shown in the upper panel of Fig. 8. The strong discontinuities seen in the figure are due to the requirement that only the 4 nearest stations are involved in the lightning location process, leading to artificially poor accuracy in the Western Pacific area where the receiving station density is higher. As discussed in Sect. 6.1, there are some parts of the world where most of the lightning locations are provided by observations from the minimum number of 4 stations. However, there are some regions where the 

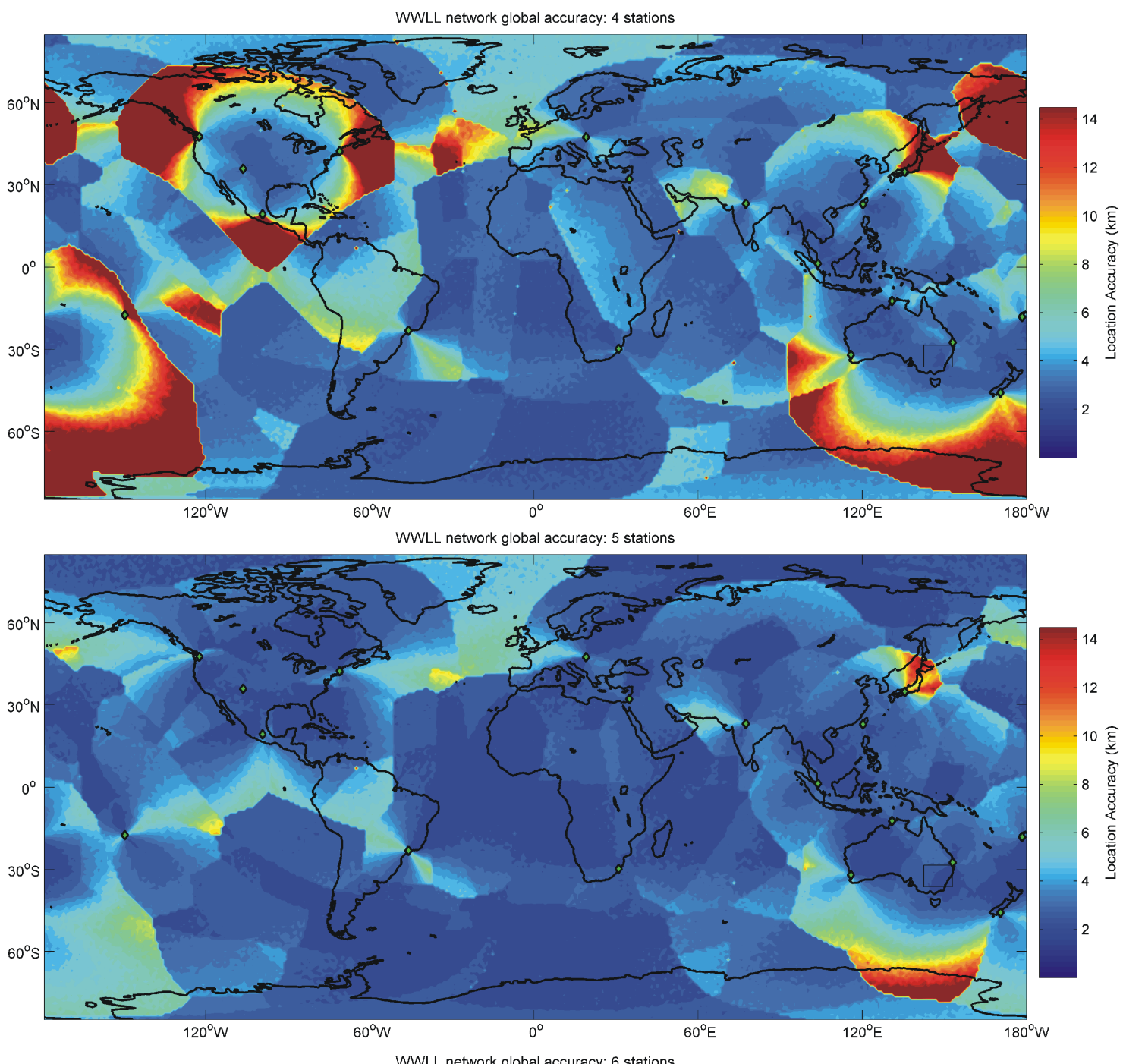

WWLL network global accuracy: 6 stations

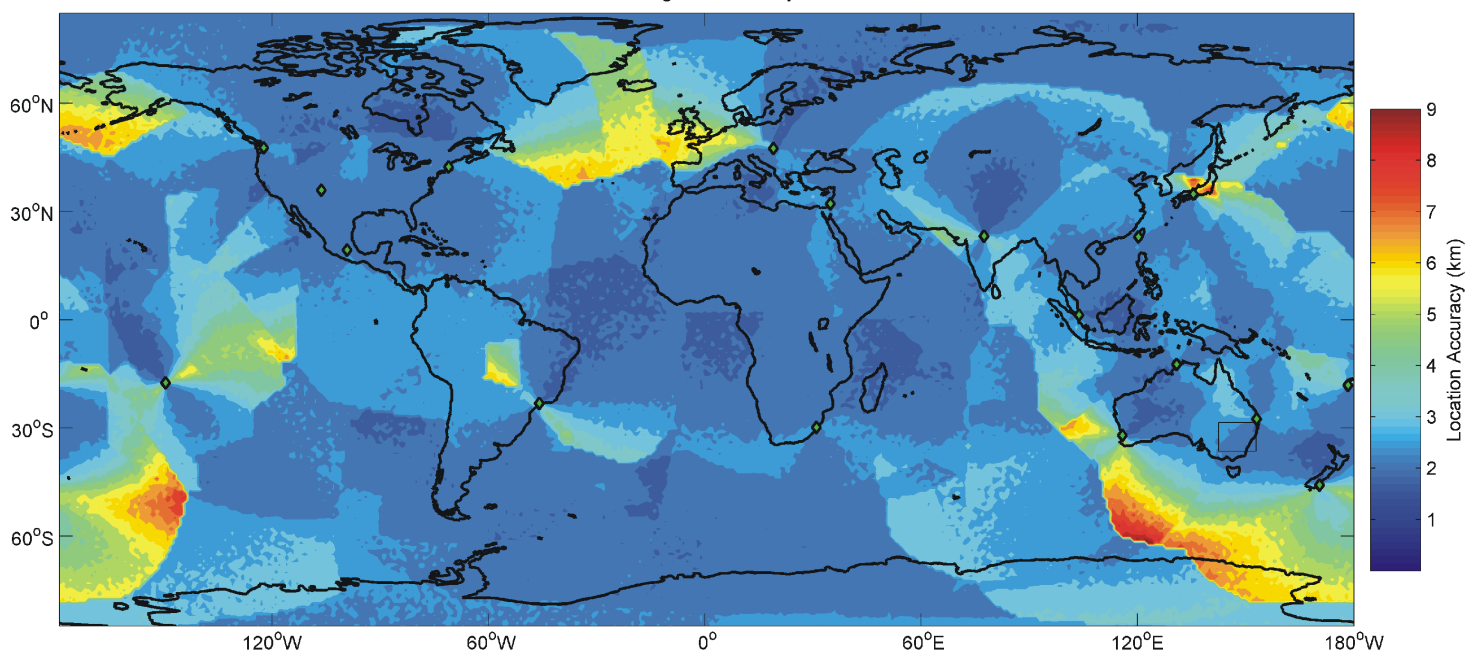

Fig. 8. An estimate of the global location accuracy of the 18 receiving station WWLL network listed in Table 1, assuming a 10- $\mu$ s timing error. The upper panel shows location accuracies assuming that only the minimum 4 receiving stations report a lightning event, while the middle and lower panels shows the same situation for 5 and 6 receiving stations, respectively. 
mean number of stations involved in each lightning location observation is as high as 6 , with the current global mean being $\sim 5$ stations. Thus, we have also produced maps of the global location accuracies assuming that the 5 or 6 nearest stations take part in locating each lightning flash, as shown in the middle and lower panels of Fig. 8, respectively. As expected the larger the number of stations involved in each discharge location, the greater the location accuracy. The global location accuracy for this network configuration assuming 5station involvement ranges over 1.9-19 km, with the global median being $2.9 \mathrm{~km}$, and the global mean $3.4 \mathrm{~km}$. This is an improvement of almost ten times over the earlier estimates (Rodger et al., 2004), reflecting the improved timing accuracy provided by the TOGA algorithm and the larger number of stations involved in a typical location.

Note that the colour scale in the lower panel of Fig. 8 (6 stations) is different from the upper two, to show the complete range of location accuracies found; in this case the location accuracy worldwide would be $<10 \mathrm{~km}$. Thus, the WWLL network could meet its location accuracy goal by retaining the current processing algorithms but boosting the sensitivity of the existing receivers (e.g. decreasing trigger thresholds). However, we note that in-situ comparisons need to be undertaken in regions far from existing WWLL stations, as the use of a globally constant Gaussian timing error derived from the oceanic comparison will not necessarily include propagation errors for lightning far from WWLL stations. Such a study was undertaken by Lay et al. (2004), who examined the location accuracy of the pre-TOGA algorithm WWLL network in Brazil in March 2003, when the closest VLF receivers were $>7000 \mathrm{~km}$ away, against a local Brazil lightning detection network. This study found that the absolute location error was $20.25 \pm 13.5 \mathrm{~km}$, which should be compared with the location accuracy estimates of Roger et al. (Fig. 11; 2004), who found that for this pre-TOGA algorithm 11-station WWLL network the estimated location accuracy would be $\sim 16-17 \mathrm{~km}$. We note that this estimate is rather similar to that demonstrated by experimental comparison, and suggests that the combination of the Monte Carlo estimation with a globally fixed Gaussian timing error derived from Australian comparisons is adequate, even in the case for extremely long-range propagation. Nonetheless we caution that the global location accuracies shown in Fig. 8 are based upon on an extrapolation taken from a comparatively small region, and cannot be considered as truthful until more direct "ground truth" comparisons are undertaken. Future studies need to be undertaken using independent lightning location data for locations elsewhere in the world, preferably using some of the well-developed large networks existing in North America or the coupled networks of Europe.

\section{Detection efficiencies February-April 2004}

We have undertaken an analysis of all $\sim 6.47$ million "good" WWLL network lightning locations (residuals $\leq 20 \mu$ s) reported over the 90 days from February-April 2004. This time period was chosen as the network configuration was reasonably stable.

\subsection{WWLL network observed lightning activity}

The upper panel of Fig. 9 shows the annualized geographical distribution of WWLL detected lightning activity (in units of flashes $\mathrm{km}^{-2} \mathrm{yr}^{-1}$ ) for February-April 2004. This should be contrasted with the lower panel of Fig. 9, which shows the annualized geographical distribution of total lightning activity taken from the Optical Transient Detector (OTD) Low Resolution Full Climatology data set (Christian et al., 2003). This represents an average picture of the lightning activity in February-April, based on 5 years of satellite observations made from low-Earth orbit. Both panels in the activity plots are calculated using the same $2.5^{\circ}$ resolution equalangle grid cells provided with the OTD data set. Note that the scales have been changed between the two panels to aide comparison; the WWLL activity levels are one-tenth of those for the OTD panel.

Clearly, some of the expected features for lightning in February-April (from the OTD observations) are present in the WWLL network lightning activity map, particularly the "maritime continent" (SE Asia and northern Australia and the Indonesian archipelago). Regions of greater lightning density in the WWLL locations generally correspond to land masses, as expected. Nonetheless, the WWLL lightning activity currently reflects the relative station densities (Fig. 1), favouring the Maritime Continent, the weaker of the three thunderstorm "chimney" regions (Orville and Henderson, 1986), over the other two regions (America and Africa). However, the strongest lightning producing region, Africa (e.g. Christian et al., 2003), is currently fairly well represented in the data when one considers the low number of stations in this region. Additional receiving stations will be required to reproduce the relative size of the activity peaks.

The effects of station density can be judged from Fig. 10, where a global map is shown of the daily mean number of receiving stations involved in each lightning location occurring from February-April 2004. The minimum number of observations required for a valid location is 4 , and hence this is the minimum number of stations shown in Fig. 10. Note that in some parts of the world most lightning locations are provided on average by only 4 stations (e.g. North America), while in parts of the Maritime Continent the average is $\sim 6$ receiving stations. This will strongly influence the location accuracies in these regions. Globally, about $45 \%$ of all events are observed by the minimum number of 4 stations, with $\sim 25 \%$ by 5 stations, and $\sim 1 \%$ reported by 10 stations. The global average for February-April 2004 is $~ 5.2$ stations involved in locating a WWLL event. Again, this is an improvement over the earlier situation and probably reflects the increased station densities, as well as improved event matching from the TOGA algorithm. 

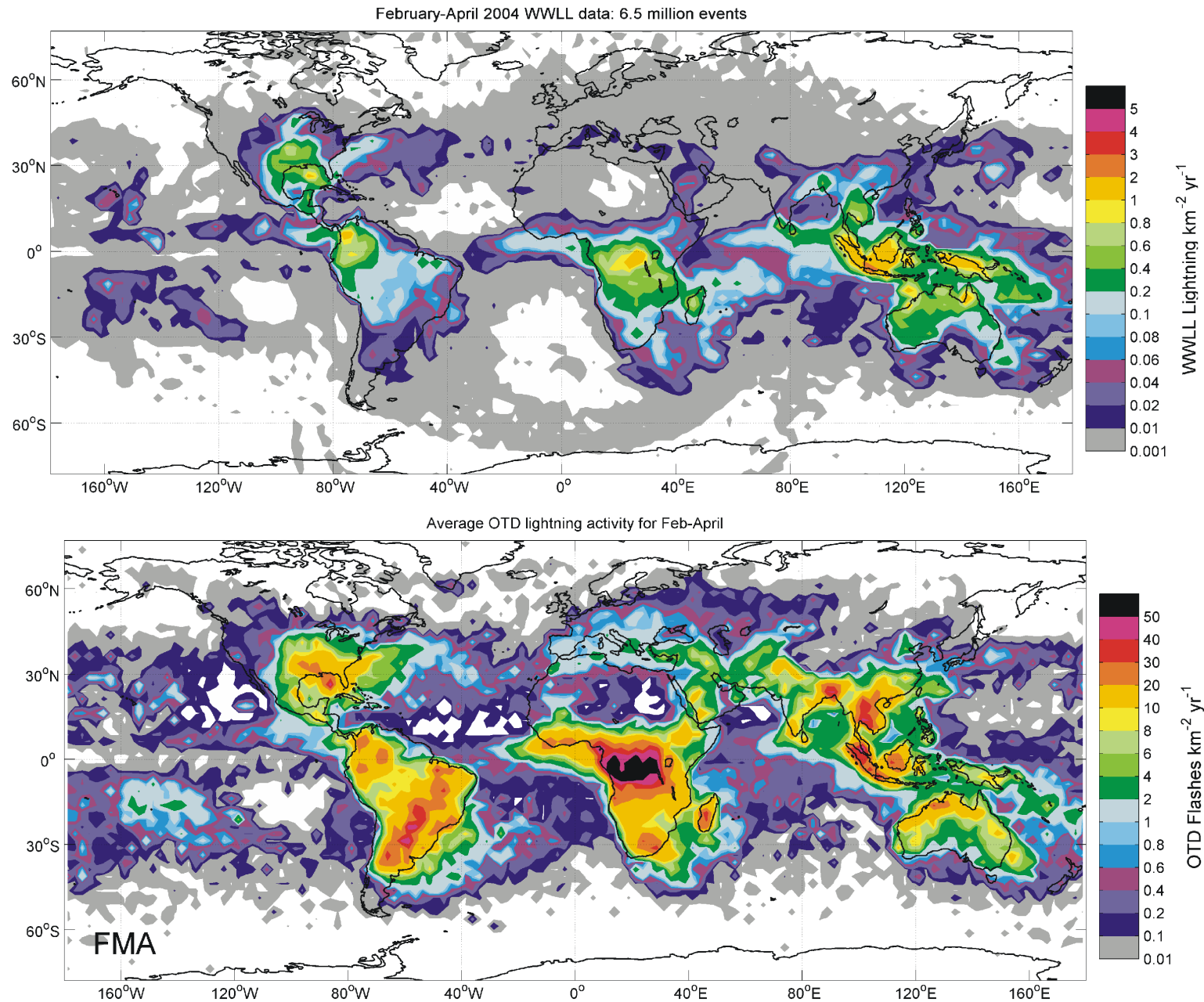

Fig. 9. The annualized geographical distribution of lightning activity in units of flashes $\mathrm{km}^{-2} \mathrm{yr}^{-1}$. The upper panel shows the good WWLL lightning locations from February-April 2004, while the lower panel are the annualized mean for these months, determined from 5 years of OTD data, after Christian et al. (2003).

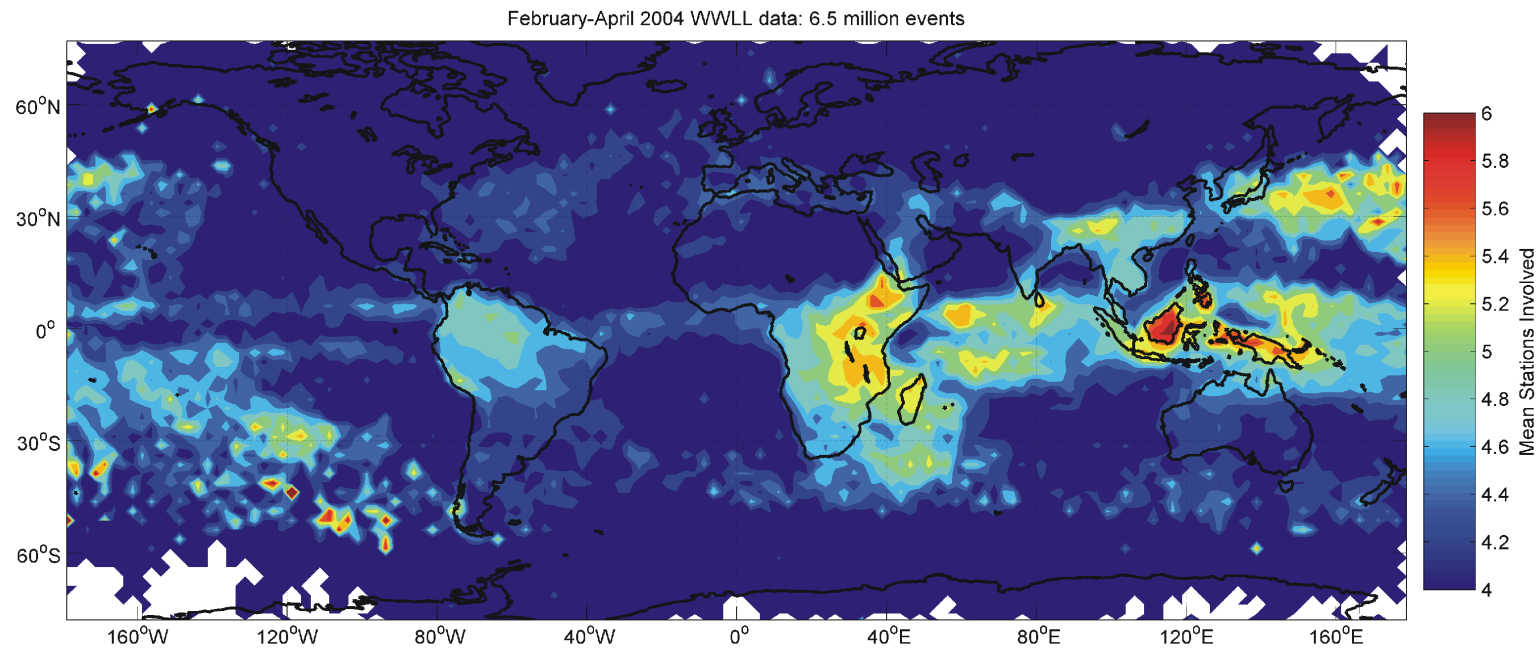

Fig. 10. Diurnal variation in the WWLL reported discharge rate. Also shown are the WWLL lightning rates for the 3 principle thunderstorm activity regions for contrast with the classic Carnegie curve. 


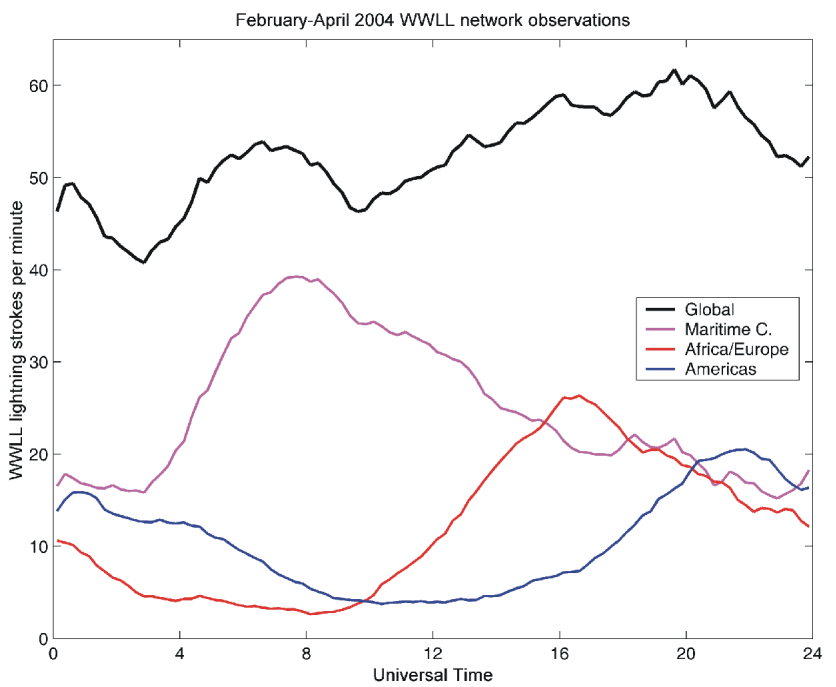

Fig. 11. Diurnal variation in the WWLL reported discharge rate. Also shown are the WWLL lightning rates for the 3 principle thunderstorm activity regions for contrast with the classic Carnegie curve.

\subsection{Diurnal variation in WWLL events}

The varying contribution of the 3 chimney regions in the WWLL observations can also be seen in the diurnal variation in the global lightning rate (Fig. 11), which has been divided up into the primary chimney regions as follows: America $\left(30^{\circ} \mathrm{W}-120^{\circ} \mathrm{W}\right)$, Africa/Europe $\left(60^{\circ} \mathrm{E}-30^{\circ} \mathrm{W}\right)$, Maritime Continent $\left(150^{\circ} \mathrm{E}-60^{\circ} \mathrm{E}\right)$. This figure should be contrasted with the classic Carnegie curve for regional thunderstorm occurrence (Whipple and Scrase, 1936), which uses the same geographical limits as our Fig. 11. While the diurnal global thunderstorm occurrence expressed through the Carnegie curve suggests that lightning activity is strongest in Africa/Europe, followed by the Americas and finally the Maritime Continent, the WWLL network has a much stronger Maritime Continent contribution, reflecting the local station density. The relative phasing between the timing of the peaks is also somewhat different, with the Africa/Europe curve peaking at $\sim 16: 50$ UT and the Americas curve at $\sim 22: 00$ UT, rather than 14:00 UT and 20:50 UT in the case of the Carnegie curve. This phasing difference may reflect the seasonal time period when the WWLL observations were made, but could also reflect the station locations.

\subsection{WWLL global detection efficiency}

We can roughly estimate the regional detection efficiency of the WWLL network from the diurnal lightning occurrence curves. Using the OTD observations we can determine the expected mean total flash rate for February-April of $\sim 39 \pm 4$ flashes per second, rather similar to the geographic global annual average figure of $44 \pm 5$ flashes per second (Christian et al., 2003). In contrast, the mean WWLL good lightning rate for February-April 2004 was $0.9 \mathrm{~s}^{-1}$, indicat- ing that the WWLL is detecting $2 \%$ of the global total lightning. However, most of the OTD total lightning rate will be due to IC flashes $\left(\sim 30 \mathrm{~s}^{-1}\right)$, assuming that there are 3.5 times more IC discharges than CG, with the remainder due to $\mathrm{CG}$ discharges. If we conservatively assume that $50 \%$ of the good WWLL events are CGs and 50\% are ICs, then the WWLL provided good locations for $\sim 5 \%$ of global CG activity. Therefore, we should ask whether it is likely that the WWLL will be able to meet the goal of a 50\% CG detection efficiency. During February-April 2004 the WWLL reported 45.5 million lightning locations (with any residual value) with an overall mean event rate of $6.1 \mathrm{~s}^{-1}$. Following the above argument, this should include $\sim 35 \%$ of the global CG activity, which is quite successful given the current station densities and (high) triggering thresholds. Clearly, the problem is that most of these locations are "bad". It is likely that the algorithm for combining TOGA observations from the globally spaced receivers is often including measurements from multiple discharges, and thus producing a large number of "bad" locations. An improved process for combining the TOGA observations is currently being developed.

\section{WWLL regional detection efficiencies}

We can also make use of the OTD global flash rates and the Carnegie curve to give a very rough estimate of the regional detection efficiencies. Taking the regional maxima in the Carnegie curves, we find that the Africa/Europe region is $\sim 90 \%$ of the total global mean flash rate at its maximum activity, America $\sim 75 \%$ and the Maritime Continent $\sim 60 \%$. For the case of the Maritime Continent, the peak total lightning flash rate should be $\sim 23 \mathrm{~s}^{-1}$ (60\% of the global mean) of which $\sim 5 \mathrm{~s}^{-1}$, will be due to CG discharges. At its peak the WWLL reports a good lightning rate of $0.65 \mathrm{~s}^{-1}$ in the Maritime Continent, which, if 50\% are due to CGs, will mean a $\sim 7 \%$ regional CG detection efficiency. Undertaking the same process for Africa/Europe and the Americas produces $\sim 3 \%$ and $\sim 2.5 \% \mathrm{CG}$ detection efficiencies, respectively. While we acknowledge that there is high uncertainly in these estimates, they do provide a rough idea of the regional detection efficiencies of the current WWLL network.

It should be noted that the true Carnegie Curve (of atmospheric electricity) and the Carnegie Curve for global lightning (as used above), are different in both amplitude and phase (see the discussion in Williams and Satori (2004) blackbox (reference missing from reference list). In general, lightning is more volatile than the integrated current in the global circuit, which has contributions beyond that of simple lightning rates, such that Carnegie Curve representing the variation in the global electrical circuit is not well explained by variation in global lightning activity. The comparison of lightning activity in the two tropical chimneys (Africa and South America) is consistent of comparisons with observations using the OTD/LIS (e.g. Christian et al., 2003) and ELF methods (e.g. Williams and Satori, 2004). 


\section{Summary}

An experimental VLF World-wide Lightning Location (WWLL) network has been developed through collaborations with research institutions across the globe. The aim of the WWLL is to provide global real time locations of lightning discharges, with $>50 \%$ CG flash detection efficiency and mean location accuracy of $<10 \mathrm{~km}$. In the last $\sim 4$ years the network has expanded from a limited number of stations in the Western Pacific to its current state of 18 stations which cover much of the globe, with additional stations planned in the near future. As part of the initial testing phase of the WWLL, the network operated in a simple mode where the station trigger times are sent to a central processing point, rather than making use of the sferic Time of Group Arrival (TOGA). The location accuracies of the pre-TOGA algorithm were reported by Rodger et al. (2004). In this paper the location accuracy of the post-TOGA algorithm WWLL network (1 August 2003) has been characterised, providing estimates of the globally varying location accuracy.

Estimates of the location accuracy have been found by comparison with commercial lightning location data purchased from an Australian network, Kattron. In total, 5006 matched lightning events were found over 13 January 2004 in a region where the Kattron location error is modelled as being $<1 \mathrm{~km}$. These matched events corresponded to slightly larger Kattron-determined lightning return stroke peak currents but with a much smaller difference than in the pre-TOGA comparison. The WWLL locations were found to have no significant systematic offsets from the Kattrondetermined locations, suggesting that an earlier problem with data in this region has been corrected.

The random errors in the radial differences (which are therefore all positive) are described by a mean of $4.2 \mathrm{~km}$ and a standard deviation of $2.7 \mathrm{~km}$. A comparison of this WWLL location accuracy in the spatial region selected with the output of a Monte Carlo simulation allows us to determine the appropriate Gaussian timing error for the WWLL network of receiving stations $(10 \mu \mathrm{s})$, and hence simulate the location errors for the existing 18-station network. Currently, the average number of stations involved in each location finding measurement is $\sim 5$. The global location accuracy for this network configuration assuming 5-station involvement ranges over $1.9-19 \mathrm{~km}$, with the global median being $2.9 \mathrm{~km}$, and the global mean $3.4 \mathrm{~km}$. This is about a factor of ten improvement over the earlier estimates (Rodger et al., 2004). The implementation of the TOGA algorithm has significantly improved the location accuracies of the WWLL network, and there is a realistic possibility of meeting the $<10 \mathrm{~km}$ accuracies for the operational network simply by retaining the current processing algorithms but boosting the sensitivity of the existing receivers (i.e. decreasing the trigger thresholds), such that $\sim 6$ stations are involved in most lightning location measurements.

The detection efficiency of the WWLL was also considered. In the selected region the WWLL detected $\sim 13 \%$ of the total lightning, suggesting a $\sim 26 \%$ CG detection efficiency and a $\sim 10 \%$ IC detection efficiency. While lower than the long-term goal of the network ( $\sim 50 \%$ CG detection), this is a considerable improvement from the earlier (pre-TOGA algorithm) detection efficiencies reported by Rodger et al. (2004). It appears that the WWLL network operates best in some parts of the Maritime Continent. Based on a comparison between all WWLL good lightning locations in February-April 2004, and the activity levels expected from satellite observations we estimate that the WWLL is currently detecting $\sim 2 \%$ of the global total lightning, providing good locations for $\sim 5 \%$ of global CG activity. The rough breakdown of CG detection efficiencies in the main lightning producing areas of the globe are Maritime Continent ( 7\%), Africa/Europe $(\sim 3 \%)$ and America $(\sim 2.5 \%)$. The network has some way to go before meeting its long-term goal for detection efficiency.

Nonetheless, the existing WWLL network is capable of providing real time positions of global thunderstorm locations in its current form. While further "ground-truth" studies of the network will be very valuable, the existing data should prove very useful for users from a wide variety of backgrounds (e.g. aviation, satellite visible and IR comparisons, detection of global change, etc.).

Acknowledgements. C. J. Rodger would also like to thank F. Grant of Dunedin for her support. He was partially supported by the New Zealand Marsden Research Fund contract 02-UOO-106, while the Australasian network activities were supported by Australian Research Council contract LP 0219331 . We thank the all the network hosts listed in Table 1 for housing the VLF lightning acquisition receivers, and Robert McCormick of the University of Otago for useful comments. We also wish to acknowledge the NASA LIS/OTD Science Team and Global Hydrology and Climate Center (GHCC) for collecting and providing the satellite observed lightning data.

Topical Editor O. Boucher thanks J. Nash, A. R. Jacobson and another referee for their help in evaluating this paper.

\section{References}

Brundell, J. B., Rodger, C. J., and Dowden, R. L.: Validation of single station lightning location technique, Radio Sci., 37(4), 10.1029/2001RS002477, 2002.

Burrows, W. R., King, P., Lewis, P. J., Kochtubajda, B., Snyder, B., Turcotte, V.: Lightning occurrence patterns over Canada and adjacent United States from Lightning Detection Network observations, J. Atmos. Oceans, 40, 59-80, 2002.

Christian, H. J., Blakeslee, R. J., Boccippio, D. J., Boeck, W. L., Buechler, D. E., Driscoll, K. T., Goodman, S. J., Hall, J. M., Koshak, W. J., Mach, D. M., and Stewart, M. F.: Global frequency and distribution of lightning as observed from space by the Optical Transient Detector, J. Geophys. Res., 108(D1), 10.1029/2002JD002347, 2003.

Crombie, D. D.: Periodic fading of VLF signals received over long paths during sunrise and sunset. Journal of Research National Bureau of Standards, Radio Science, 68D, 27-34, 1964.

Cummer, S. A., Inan, U. S., and Bell, T. F.: Ionospheric D region remote sensing using VLF radio atmospherics, Radio Sci. 33, 1781-1792, 1998.

Cummins, K. L. and Murphy, M. J.: Overview of lightning detection in the VLF, LF, and VHF frequency ranges, 2000 Interna- 
tional Lightning Detection Conference, Tucson, Arizona, 1-10, 2000.

Cummins, K. L., Krider, E. P., and Malone, M. D.: The U.S. National Lightning Detection Network and applications of cloudto-ground lightning data by electric power utilities, IEEE Trans. Electromagn. Comp., 40(4), 465-480, 1998a.

Cummins, K. L., Murphy, M. J., Bardo, E. A., Hiscox, W. L., Pyle, R. B., and Pifer, A. E.: A combined TOA/MDF technology upgrade of the U.S. National Lightning Detection Network, J. Geophys. Res, 103, 9035-9044, 1998b.

Dowden, R. L., Brundell, J. B., and Rodger, C. J.: VLF lightning location by time of group arrival (TOGA) at multiple sites, J. Atmos. Sol. Terr. Phys., 64, 817-830, 2002.

Fullekrug, M. and Constable, S.: Global triangulation of intense lightning discharges, Geophys. Res. Lett., 27(3), 333-336, 2000.

Hamid, E. F., Kawasaki, Z-I., and Mardiana, R.: Impact of the 1997-1998 El Niño event on lightning activity over Indonesia, Geophys. Res. Lett., 28, 147-150, 2001.

Huang, E., Williams, E., Boldi, R., Heckman, S., Lyons, W., Taylor, M., Nelson, T., and Wong, C.: Criteria for sprites and elves based on Schumann resonance observations, J. Geophys. Res., 104(D14), 16 943-16 964, 10.1029/1999JD900139, 1999.

Jourdain, L. and Hauglustaine, D. A.: The global distribution of lightning NOx simulated on-line in a general circulation model, Phys. Chem. Earth Pt. C-Solar-Terr. Planet. Sci, 26, 585-591, 2001.

Knupp, K. R., Paech, S., and Goodman, S.: Variations in cloud-toground lightning characteristics among three adjacent tornadic supercell storms over the Tennessee valley region, Mon. Weather Rev., 131, 172-188, 2003.

Lay, E. H., Holzworth, R. H., Rodger, C. J., Thomas, J. N., Pinto, O., and Dowden, R. L.: WWLL Global Lightning Detection System: Regional Validation Study in Brazil, Geophys. Res. Lett., 31(3), L03102, 10.1029/2003GL018882, 2004.

Lee, A. C. L.: An experimental study of the remote location of lightning flashes using a VLF arrival time difference technique, Q. J. Royal Met. Soc., 112, 203-229, 1986.

Lyons, W. A., Nelson, T. E., Williams, E. R., Cramer, J. A., and Turner, T. R.: Enhanced positive cloud-to-ground lightning in thunderstorms ingesting smoke from fires, Science, 282, 77-80, 1998.

MacGorman, D. R. and Rust, R. W.: The Electrical Nature of Storms, Oxford University Press, Oxford, 1998.

Mackerras, D., Darveniza, M., Orville, R. E., Williams, E. R., and Goodman, S. J.: Global lightning: Total, cloud and ground flash estimates. J. Geophys. Res., 103, 19791-19809, 1998.

Magono, C.: Thunderstorms, Elsevier Sci., Amsterdam, 1980.

Morales, C. A., Weiman, J. A., Anagnostou, E. N., Goodman, S., and Williams, E.: Continuous Long-Range Thunderstorm Monitoring by a VLF Receiver Network: Location Error Analysis and Cloud-to-Ground and Intra-Cloud Detection Efficiency, J. Atmos. Ocean. Tech., in press, 2004.
Orville, R. E.: Lightning Detection from Ground and Space, in Handbook of atmospheric electrodynamics; Vol. 1, 2nd ed., edited by H. Volland, 137-149, CRC Press, Boca Raton, Fl., 1995.

Orville, R. E. and Henderson, R. W.: Global distribution of midnight lightning, September 1977 to August 1978, Mon. Wea. Rev., 114, 2640-2653, 1986.

Pierce, E. T.: Atmospherics and radio noise, in Lightning, vol. 1, edited by R. H. Golde, Academic Press, New York, 309-350, 1977.

Rakov, V. A. and Uman, M. A.: Lightning; Physics and Effects, Cambridge University Press, Cambridge, 2003.

Rodger, C. J., Brundell, J. B., Dowden, R. L., and Thomson, N. R.: Location accuracy of long distance VLF lightning location network, Ann. Geophys., 22, 747-758, 2004,

SRef-ID: 1432-0576/ag/2004-22-747.

Rodger, C. J., Clilverd, M. A., and McCormick, R. J.: Significance of lightning generated whistlers to inner radiation belt electron lifetimes, J. Geophys. Res., 108, 1462, 10.1029/2003JA009906, 2003.

Rodger, C. J.: Red sprites, upward lightning, and VLF perturbations, Rev.Geophys., 37, 317-336, 1999.

Schlegel, K., Diendorfer, G., Thern, S., and Schmidt, M.: Thunderstorms, lightning and solar activity - Middle Europe, J. Atmos. Sol.-Terr. Phys., 63, 1705-1713, 2001.

Thomas, R. J., Krehbiel, P. R., Rison, W., Hamlin, T., Boccipio, D. J., Goodman, S. J., and Christian, H. J.: Comparison of ground-based 3-dimensional lightning mapping observations with satellite-based LIS observations in Oklahoma, Geophys. Res. Lett., 27, 1703-1706, 2000.

Uman, M. A.: The Lightning Discharge, Int. Geophys. Ser., Vol. 39, Academic Press, San Diego, Calif., 1987.

Whipple, F. J. W. and Scrase, F. J.: Point discharge in the electric field of the earth, Met. Office Geophys. Mem. London, VII68, 3-20, 1936.

Williams, E. R.: The Schumann Resonance: A global tropical thermometer, Science, 256, 1184-1187, 1992.

Williams, E. R. and Sartori, G.: Lightning, thermodynamic and hydrological comparison of the two tropical continental chimneys, J. Atmos. S-P, 66, 1213-1231, 2004.

Wood, T. G. and Inan, U. S.: Long-range tracking of thunderstorms using sferic measurements, J. Geophys. Res., 107, 4553, 10.1029/2001JD002008, 2002.

Yair Y., Israelevich, P., Devir, A. D., Moalem, M., Price, C., Joseph, J. H., Levin, Z., Ziv, B., Sternlieb, A., and Teller, A.: New observations of sprites from the space shuttle, J. Geophys. Res., 109, D15201, doi:10.1029/2003JD004497, 2004. 